\title{
Cerebral autosomal dominant arteriopathy with subcortical infarcts and leukoencephalopathy revisited
}

\author{
Genotype-phenotype correlations of all published cases
}

Georgia Xiromerisiou, MD, PhD, Chrysoula Marogianni, MD, MSc, Katerina Dadouli, MSc, Christina Zompola, MD, Despoina Georgouli, MD, MSc, Antonios Provatas, MD, PhD, Aikaterini Theodorou, MD, Paschalis Zervas, MD, Christina Nikolaidou, MD, Stergios Stergiou, MD, Panagiotis Ntellas, MD, Maria Sokratous, MD, MSc, Pantelis Stathis, MD, PhD, Georgios P. Paraskevas, MD, PhD, Anastasios Bonakis, MD, PhD, Konstantinos Voumvourakis, MD, PhD, Christos Hadjichristodoulou, MD, PhD, Georgios M. Hadjigeorgiou, MD, PhD, and Georgios Tsivgoulis, MD, PhD

Neurol Genet 2020;6:e434. doi:10.1212/NXG.0000000000000434

\begin{abstract}
Objective

The aim of this study was to evaluate the correlation between the various NOTCH3 mutations and their clinical and genetic profile, along with the presentation of a novel mutation in a patient.
\end{abstract}

\section{Methods}

Here, we describe the phenotype of a patient with cerebral autosomal dominant arteriopathy with subcortical infarcts and leukoencephalopathy (CADASIL) harboring a novel mutation. We also performed an extensive literature research for NOTCH3 mutations published since the identification of the gene and performed a systematic review of all published cases with $\mathrm{NOTCH} 3$ mutations. We evaluated the mutation pathogenicity in a great number of patients with detailed clinical and genetic evaluation and investigated the possible phenotype-genotype correlations.

\section{Results}

Our patient harbored a novel mutation in the NOTCH3 gene, the c.3084 G > C, corresponding to the aminoacidic substitution p.Trp1028Cys, presenting with seizures as the first neurologic manifestation. We managed to find a correlation between the pathogenicity of mutations, severity of the phenotype, and age at onset of CADASIL. Significant differences were also identified between men and women regarding the phenotype severity.

\section{Conclusions}

The collection and analysis of these scarce data published since the identification of NOTCH3 qualitatively by means of a systematic review and quantitatively regarding genetic profile and pathogenicity scores, highlight the significance of the ongoing trend of investigating phenotypic genotypic correlations.

\author{
Correspondence \\ Dr. Xiromerisiou \\ georgiaxiromerisiou@gmail.com
}




\section{Glossary}

CADASIL = cerebral autosomal dominant arteriopathy with subcortical infarcts and leukoencephalopathy; CADD = combined annotation-dependent depletion; $\mathbf{C I}=$ confidence interval; $\mathbf{C M B}=$ cerebral microbleed; $\mathbf{E C D}=$ extracellular domain; $\mathbf{E G F r}=$ epidermal growth factor-like repeat; GOM = granular osmiophilic material; TIA = transient ischemic attack.

Cerebral autosomal dominant arteriopathy with subcortical infarcts and leukoencephalopathy (CADASIL) is the most common heritable cause of stroke in adults younger than 65 years old. ${ }^{1}$ Although the description of the first case was made around $1955,{ }^{2}$ the official characterization of the disorder was defined in 1993 after the discovery of the responsible gene, $\mathrm{NOTCH} 3$ on chromosome $19 .^{3}$ Although the clinical manifestations of the disease are directly linked to the brain lesions, there is a systemic arteriopathy that affects the skin, the spleen, the liver, the kidneys, and the aorta apart from the brain. ${ }^{4}$

CADASIL consists of 4 basic clinical characteristics, which are migraine with aura, relapsing episodes of transient ischemic attacks (TIAs) and ischemic strokes, psychiatric symptoms as apathy and severe mood swings, and gradual cognitive impairment, which eventually lead to severe dementia. ${ }^{3}$

Another fundamental element of this disorder is the leukoencephalopathy and the subcortical infracts identified on the brain MRI, especially in the external capsules and anterior pole of temporal lobes. ${ }^{5}$

Pathologic findings have confirmed the extensive changes in the brain parenchyma, compatible with chronic small artery disease, mainly affecting the white matter in the periventricular areas and the region of basal ganglia. It is worth mentioning that the cortex, which appeared unaffected in neuroimaging, in a macroscopic examination displays extended neuronal apoptosis. Furthermore, in microscopic testing of the brain lesions, a specific arteriopathy has been revealed in which there is a thickening of the arterial wall of small penetrating cerebral and leptomeningeal arteries, leading to lumen stenosis. ${ }^{6}$ At the same time, with an electronic microscope in a specimen from a pathologic skin biopsy, deposits of granular osmiophilic material (GOM) located in the basement membrane of smooth muscle cells can be identified. ${ }^{7}$ CADASIL is the only disorder whose GOM has been identified. However, some reports on the sensitivity of detecting GOM in skin biopsy of patients with genetically proven CADASIL have been contradictory. ${ }^{8,9}$

CADASIL is an autosomal dominant inherited arteriopathy caused by mutations in the NOTCH3. The NOTCH3 gene encodes a single pass transmembrane protein, with receptor properties. This receptor is mainly expressed in the smooth muscle cells of blood vessels and pericytes. ${ }^{10}$ After ligand binding, the intracellular part translocates to the nucleus and activates transcription factors. NOTCH3 has 33 exons, but all the mutations found are located in exons $2-24$, which are responsible for encoding 34 epidermal growth factor repeats,
EGFR. Most of these mutations are missense mutations, although there are only a few in-frame deletions or splice-site mutations. ${ }^{11}$ The gene mutation analysis of NOTCH3 is the gold standard to diagnose this genetically inherited disease, and there are more than 230 different mutations located in 20 different exons reported in patients with CADASIL. ${ }^{12}$

In this review, we report a patient with CADASIL with a novel heterozygous $\mathrm{NOTCH} 3$ mutation and epileptic seizures as the very first manifestation of the disorder. In silico analysis revealed the pathogenicity of the mutation. However, we proceeded to the skin biopsy to detect deposits of GOM.

In addition, we performed a systematic review of all published cases with NOTCH3 mutations. We evaluated the mutation pathogenicity in all previously reported cases to investigate possible phenotype-genotype correlations.

\section{Methods}

\section{Case description: clinical findings}

A 62-year-old woman visited the outpatient stroke clinic of a tertiary care stroke center in Athens, Greece. The patient experienced episodes of loss of consciousness, some of them accompanied by tonic contraction of the upper arms and bite of her tongue, for the past 40 years. She has been receiving an antiepileptic drug (levetiracetam $1250 \mathrm{mg}$ daily) for the past 2 years because of repeat episodes of tonic-clonic seizures. She had also experienced an ischemic lacunar stroke in the distribution of the left middle cerebral artery 4 months before her visit to the outpatient clinic of our department that resulted in right hemiparesis. The patient's husband and children reported changes in her personality and cognitive decline, gradually worsening over the past 5 years. Her family history revealed a brother with epilepsy and a father with posttraumatic epilepsy who died at the age of 60 years old.

The patient had no history of hypertension or diabetes or other known cardiovascular risk factors. She was receiving escitalopram $(20 \mathrm{mg})$ for depression, levetiracetam $(1250 \mathrm{mg})$ for seizures, clopidogrel $(75 \mathrm{mg})$, and atorvastatin $(20 \mathrm{mg})$ for secondary stroke prevention.

The patient was admitted in our department for further diagnostic workup. We repeated brain MRI that revealed extensive bilateral white matter lesions located mainly in the frontal lobes, the anterior temporal lobe, the external capsules, the centrum semiovale, and the basal ganglia (figure 1, A-C). There was no evidence of acute infarction. Furthermore, multiple cerebral microbleeds (CMBs) located predominantly in the thalami were 
Figure 1 Brain MRI scan $(A-C)$ of the patient showing extensive leukoencephalopathy, mainly in the frontal lobes, the anterior temporal lobe, the external capsules, and the basal ganglia in the FLAIR sequences (D-F) of the daughter showing multiple hyperintensities in the FLAIR sequences
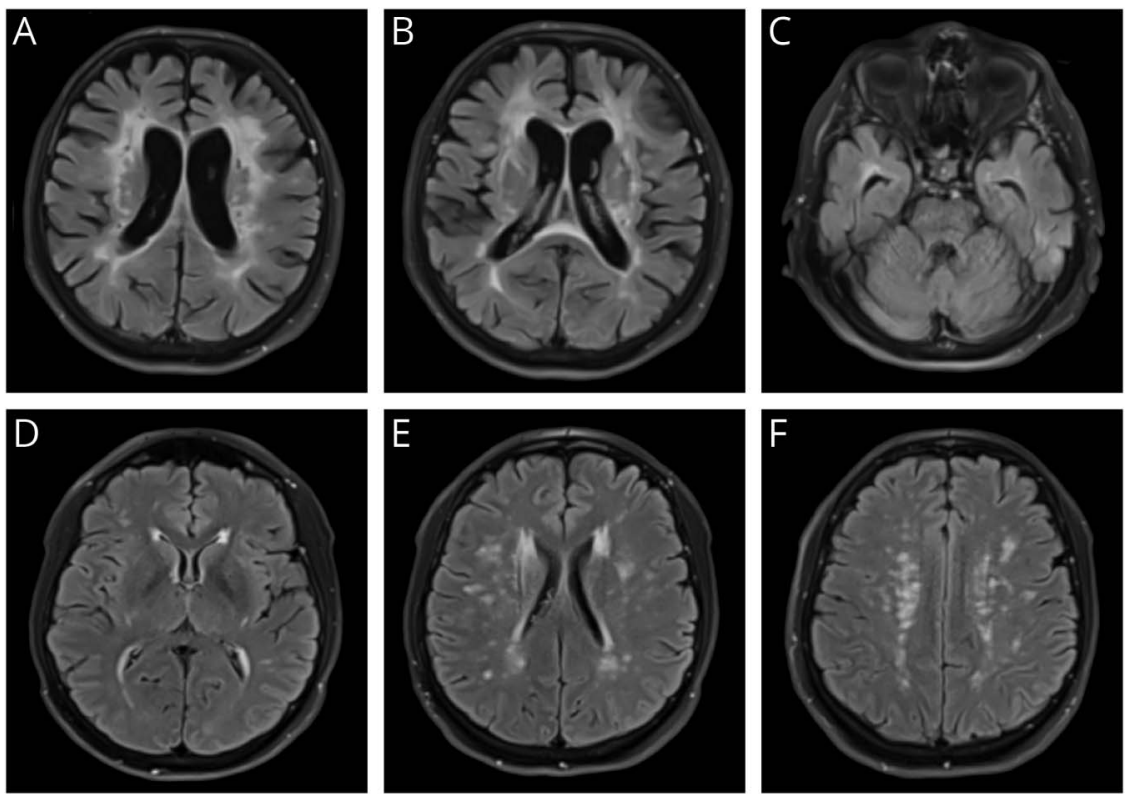

documented on susceptibility-weighted imaging. The patient underwent an extensive workup for stroke (including transesophageal echocardiography, neck, and brain MR angiography, full coagulation disorder panel, repeat 24-hour holter ECG recordings, molecular genetic screening for Fabry disease, immunologic screening for autoimmune disorders) that was unremarkable. We also found no evidence for demyelinating CNS disorder on CSF analysis (normal results with absent oligoclonal bands) and cervical as well as thoracic spinal cord MRI.

Bedside neuropsychologic examination showed moderate cognitive decline (Mini-Mental State Examination 20/30) with defects, mainly in the attention and recall ability and a Frontal Assessment Battery (6 of 18 ) that revealed a serious disorder in conceptualization and mental flexibility.

The patient's daughter complained of chronic tension-type headaches and was further investigated with brain MRI that revealed multiple hypertense subcortical white matter lesions (figure 1, D-F). The patient's son was asymptomatic and refused to undergo brain MRI despite our suggestions.

\section{Case description: genetic analysis}

Given the aforementioned extended workup, the relevant clinical course, the symptoms, and the compatible neuroimaging, the suspicion of CADASIL was raised, so we proceeded to NOTCH3 genetic analysis. Based on the mode of inheritance, the age at onset, and the phenotype, we suspected a genetic disorder. All study participants provided written informed consent for further genetic analysis. Our study was approved by the Ethics Committee of the University Hospital of Attikon. Genomic DNA of all available family members was extracted from the peripheral white blood cells according to the standard protocols.

The NOTCH3 analysis led to the identification of a heterozygous mutation in the exon 19 NOTCH3 gene, c.3084 G > C, corresponding with the amino acid substitution p.Trp1028Cys. This is a novel mutation, compatible with CADASIL syndrome, leading to the gain of a cysteine residue in one of the 34 epidermal growth factor-like repeat (EGFr) domains of the protein encoded by NOTCH3 (1,312). This results in an uneven number of cysteine residues in the given EGFr domain, most likely modifying the tertiary structure of the protein.

According to the American College of Medical Genetics and Genomics and the Association for Molecular Pathology 2015 guidelines, the pathogenicity potential of the p.Trp1028Cys variant is "pathogenic" based on the following criteria: (1) null variant (PVS1) - a missense mutation leading to a gain of a cysteine residue, (2) the absence of the variant from the controls in the Exome Sequencing Project, 1,000 Genomes Project, or Exome Aggregation Consortium (PM2), (3) in silico bioinformatics tools (Homologene, GEPR, Varsome) predicted that the variant causes a deleterious effect on the gene (PP3) because it occurs in a highly conserved area across multiple species accordingly (ncbi.nlm.nih.gov/homologene), and (4) the patient's phenotype is highly specific for the disease (PP4).

\section{Case description: histopathologic staining}

For immunohistochemistry, we used 10 -lm tissue specimens. Endogenous peroxidase activity was eliminated by treatment with $0.5 \%$ periodic acid solution for 10 minutes. The sections 


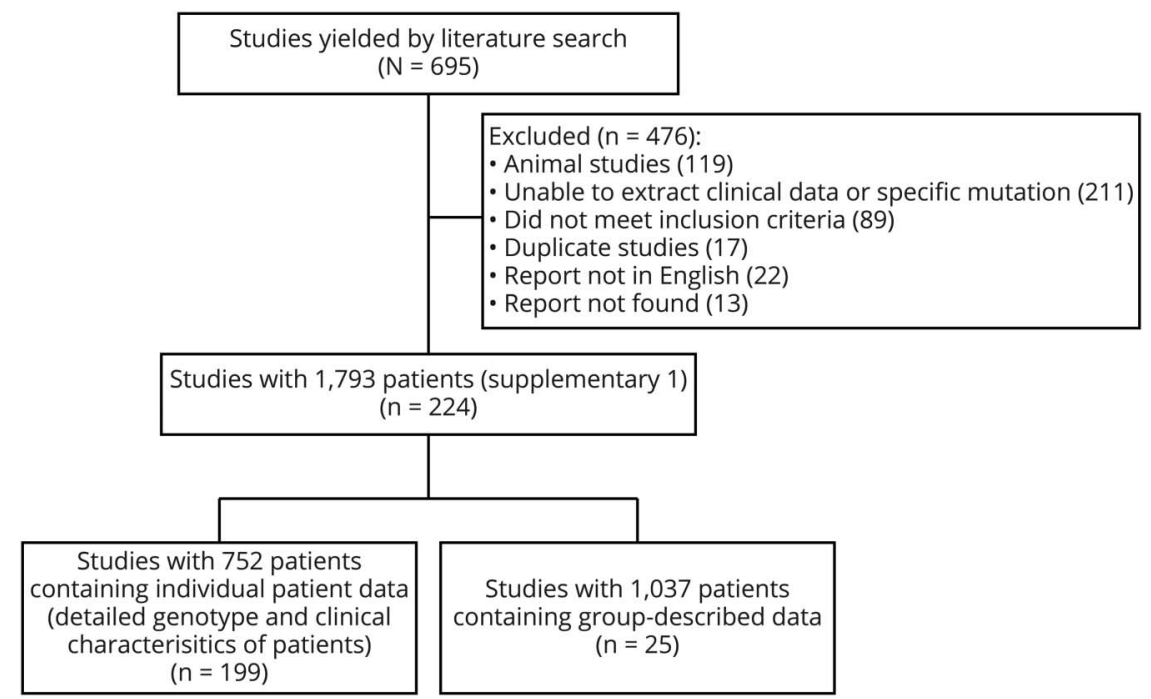

were incubated in a blocking buffer ( $1 \%$ bovine serum albumin and $5 \%$ rabbit serum in phosphate-buffered saline). A monoclonal antibody against the extracellular domain of NOTCH3 diluted 1:100 in blocking buffer, served as the primary antibody. The sections were counterstained with Victoria blue. To observe the internal elastic lamina of vascular walls, we used Victoria blue-hematoxylin and eosin staining. No specific immunoreactive signal was detected in the vessels; therefore, the specimen was scored as negative.

\section{Review of published CADASIL data}

\section{Systematic search}

We conducted a systematic review of the literature, investigating all known mutations of $\mathrm{NOTCH} 3$ and their phenotypic characteristics. We performed searches on PubMed, Cochrane Library, and MEDLINE (via PubMed) to identify all published studies before August 2019. A combination of the terms "CADASIL," "Cerebral autosomal dominant arteriopathy with subcortical infarcts and leukoencephalopathy," "NOTCH3," and "NOTCH3 MUTATIONS" were used. All studies presenting original data that reported the clinical, genetic, and radiologic characteristics of patients with CADASIL were included for further review. English language was the only filter used initially. References of selected articles and reviews were also searched for additional records.

Data extracted from each study were title; author; year of publication; the exon, the mutation and the exact amino acid change, the total cases screened carrying the mutant allele and sociodemographic characteristics (origin, age, and sex), age at onset, family history, clinical features of the disease (migraine, stroke, psychiatric disorders, cognitive decline, acute encephalopathy, and atypical findings), and findings from diagnostic procedures (MRI findings and skin biopsy).

\section{Data collection and eligibility criteria}

Studies were selected when they met the following criteria: (1) diagnosis of CADASIL was confirmed by a mutation analysis, (2) clinical findings of CADASIL were described, (3) the identified mutation was described, (4) when the same patient population was presented in more than one publication, the one with the largest sample size or most recent publication date was used as the primary study for data extraction, (5) languages being limited to English, and (6) Full study.

\section{Evaluation of mutations}

For the evaluation of the pathogenicity of the published mutations, computational prediction analysis was used. A combined annotation-dependent depletion (CADD) algorithm was used for scoring the deleteriousness of single nucleotide variants and insertion/deletions on the function of NOTCH3. Prediction is based on empirical rules applied to the sequence, phylogenetic, and structural information characterizing the amino acid substitution. ${ }^{13,14}$ A qualitative characterization of the mutations was based on the score: the CADD score is above $>30$, was highly pathogenic, above $>20$ was pathogenic, between 15 and 20 was likely pathogenic, below $<15$ was likely benign, and finally below $<10$ was benign. The Human Splicing Finder tool 37 was used to evaluate mutations that potentially affect splicing. ${ }^{15}$

\section{Statistical analysis}

We used descriptive statistics to present demographic, clinical, and other characteristics of the patients overall. Data were checked for deviation from normal distribution (Shapiro-Wilk normality test). Categorical data were analyzed with the use of a $\chi^{2}$ test; Student $t$ test, Mann-Whitney $U$ test, analysis of variance, Kruskal-Wallis test and were performed for continuous data as appropriate. Spearman correlation analyses were used to estimate the correlations between quantitative variables. A multivariate analysis was performed in the form of multiple linear regression and 


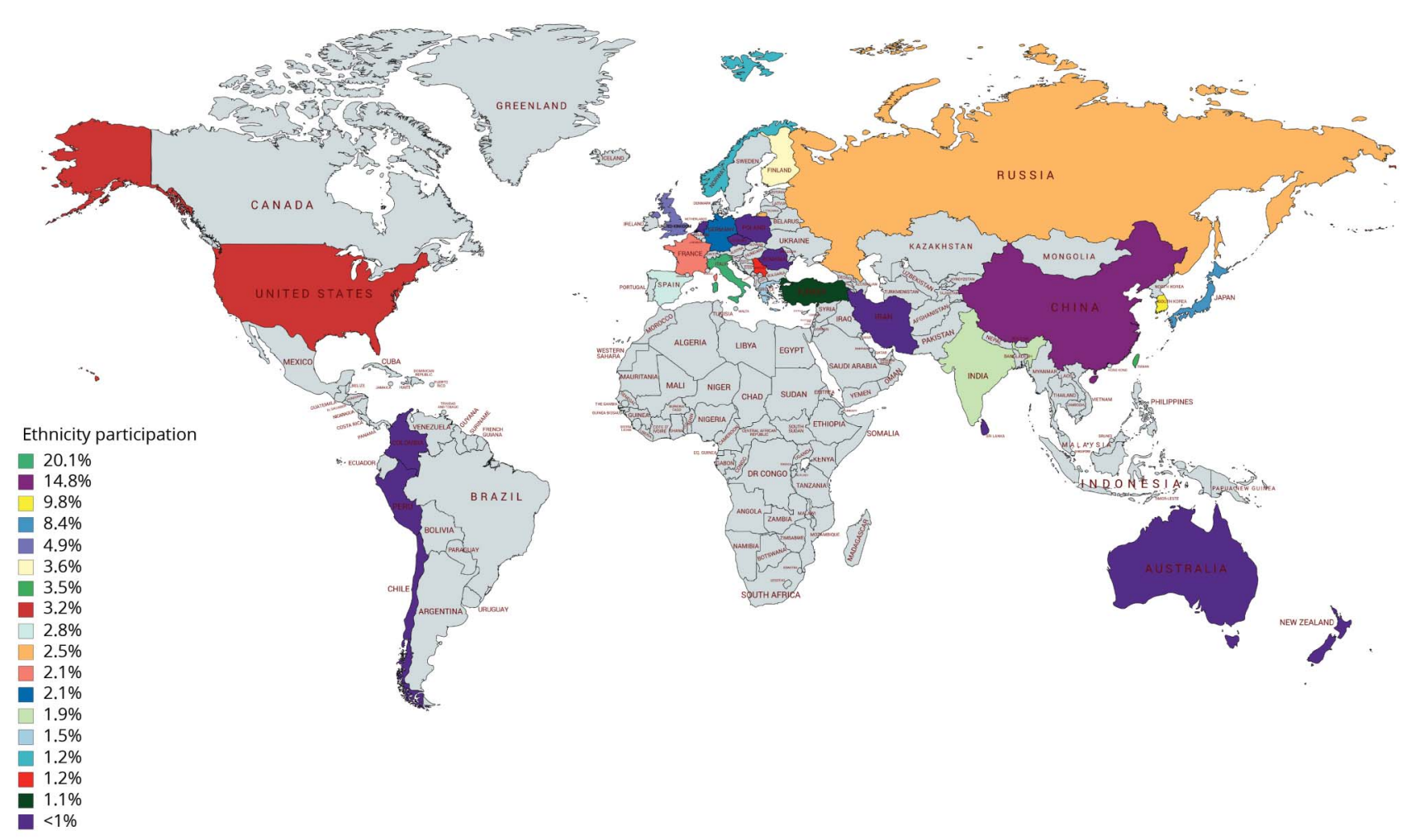

multinomial regression and multinomial (polytomous) logistic regression. The cutoff value of age at onset was calculated using the receiver operating characteristic curve. For all the analyses, a $5 \%$ significance level was set. The Bonferroni method was used to correct the significance level where it was necessary. ${ }^{16,17}$ The analysis was carried out with SPSS version 25.0.

\section{Results}

\section{Literature review}

We screened a total of 695 articles yielded by our literature search; we excluded 476 that evaluated animal models, lacked clinical, and genetic data and that were duplicates. After fulltext retrieval and review, we included the 224 remaining articles because they met the predefined eligibility criteria and we proceeded in the qualitative analysis (Supplementary 1, links.lww.com/NXG/A262). The selected studies consisted of noncontrolled case series and case reports (figure 2).

\section{Demographics: clinical phenotype}

A total of 752 patients ( $50 \%$ men) were included in our systematic review. Most of the patients were Caucasians of European origin (45\%) and Asians followed with 43\%. Only a few patients were included originating from North and South America, Africa, and Australia/New Zealand. Most case reports and small case series report patients originated from Japan,
China, and Italy. The frequencies of CADASIL mutations across various countries according to our reviewed cases are presented in a world map shown in figure 3. However, the largest case series with CADASIL that were excluded from our analysis because of the lack of detailed clinical and genetic information originated from the Netherlands, Germany, UK, and Japan.

Detailed clinical information was available for 752 patients. The overall mean age of the reported cases was $52 \pm 14$ years, whereas the mean age at onset was $43 \pm 14$ years. Apprimately $64 \%$ of the patients that have been included in the study had a positive family history, $10 \%$ had no family history, and no information was available for the remaining $25 \%$.

Migraine was reported in 23\% of patients. Most of all reported cases presented with stroke (52\%), followed by cognitive decline $(46 \%)$ while psychiatric disorders had a prevalence of $24 \%$. Psychiatric disorders included predominantly depressive symptoms, apart from a minority of cases with bipolar disorder ( 2 cases) and psychosis (1 case). Epileptic disorders were reported in $4 \%$ of the patients.

There are certain clinical characteristics mentioned in the included studies, which are atypical or in some cases, could be explained from the recurrent stroke episodes that the patients suffered. For example, we have found sensory deficits of the upper arms and findings of polyneuropathy in 10 cases. Furthermore, 


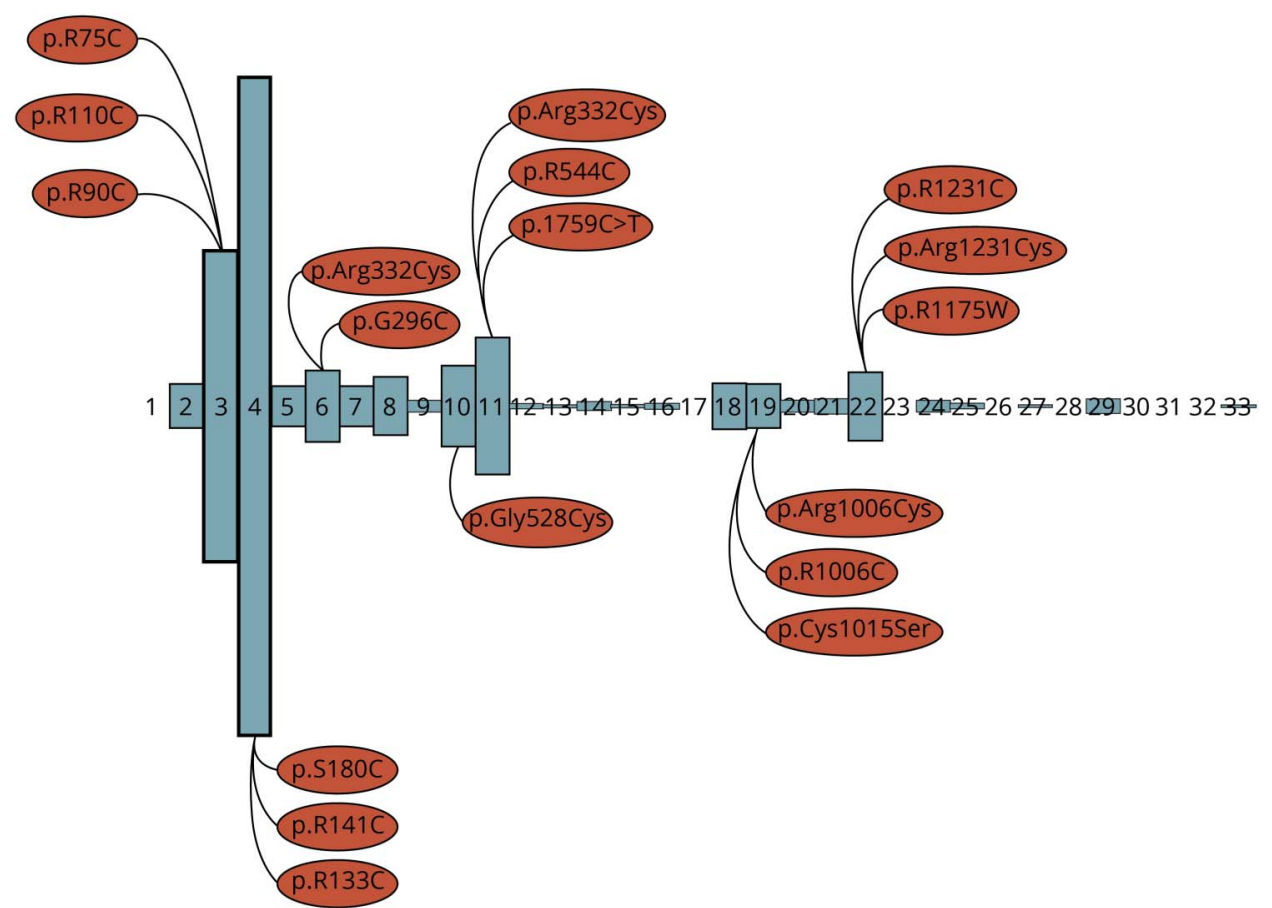

several cases (approximately 7\%) with intracerebral hemorrhage have been described. An interesting fact is the presence of movement disorders such as ataxia and parkinsonism in approximately $4 \%$ of our included patients. Symptoms such as dizziness, vertigo, gait disturbance, and dysarthria could probably be consequences of the recurrent strokes. At some point in the course of their disease, approximately $2 \%$ of patients presented a confusional state and/or encephalopathy (CADASIL coma) after severe headache that lasted several days. ${ }^{18,19}$

We divided the patients according to the presentation of one or a combination of 2 or all of the above major clinical characteristics [phenotype $1=$ patients with migraine, phenotype 2 = patients with migraine and stroke or stroke only, and phenotype $3=(1)$ patients with migraine and stroke and cognitive disorder and/or psychiatric disorder and (2) patients with stroke and cognitive decline and/or psychiatric disorder]. We noticed that most patients, 34\%, presented with phenotype 3 followed by phenotype 2 (32\%). Phenotype 1 was documented in $7 \%$ of the patients included in this systematic review.

\section{Neuroimaging and skin biopsy}

The predominant radiologic manifestations of CADASIL on the brain MRI include hyperintense located in the white matter of the anterior temporal poles, centrum semiovale, external capsule, basal ganglia, and pons. Most of the patients had radiologic signs of leukoencephalopathy in their brain MRI scans (72\%), where the precise distribution of the white matter lesions was not mentioned in most of them. We did not find any information in $25 \%$ of the patients regarding the presence of white matter lesions. Furthermore, CMBs have been reported in $7 \%$ of cases and were absent in $28 \%$ of the brain MRI scans. However, in most cases (65\%), the presence of microbleeds was not reported.

Skin biopsy data, a sensitive diagnostic tool in the diagnosis of CADASIL, were not available for more than half of the reported cases. Approximately 39\% of patients had been tested with a skin biopsy. Approximately $14 \%$ of the patients had compatible findings with the diagnosis of CADASIL, whereas $24 \%$ were tested negative for the characteristic granular deposits in the basal lamina of blood vessels. In most studies, GOM was confirmed with electron microscopy, whereas in the rest of them with immunohistochemistry.

\section{Mutations}

Most mutations described were located in the exon 4 (29\%), followed by exon $3(14 \%)$, exon $11(8 \%)$, and exon $19(6 \%)$ (figure 4). Most of the mutations are predicted to result in a gain or loss of at least one of a cysteine residue; $14 \%$ of the mutations described did not involve a cysteine residue. Most mutations were missense mutations (74\%), whereas a few splicing mutations and deletions were also reported. In total, $85 \%$ of these mutations were pathogenic and $12 \%$ were found to be highly pathogenic, whereas approximately $1 \%$ corresponded to benign mutations. Regarding quantitative pathogenicity scores, the mean score was $26(\max =44, \min =0.6$, $\mathrm{SD}=4)$. The most common mutation was p.R169C in exon 4, followed by p.R182C in the same exon. 
Figure 5 Univariate analysis showing the effect of pathogenicity score of the mutations on the age at onset of the disorder

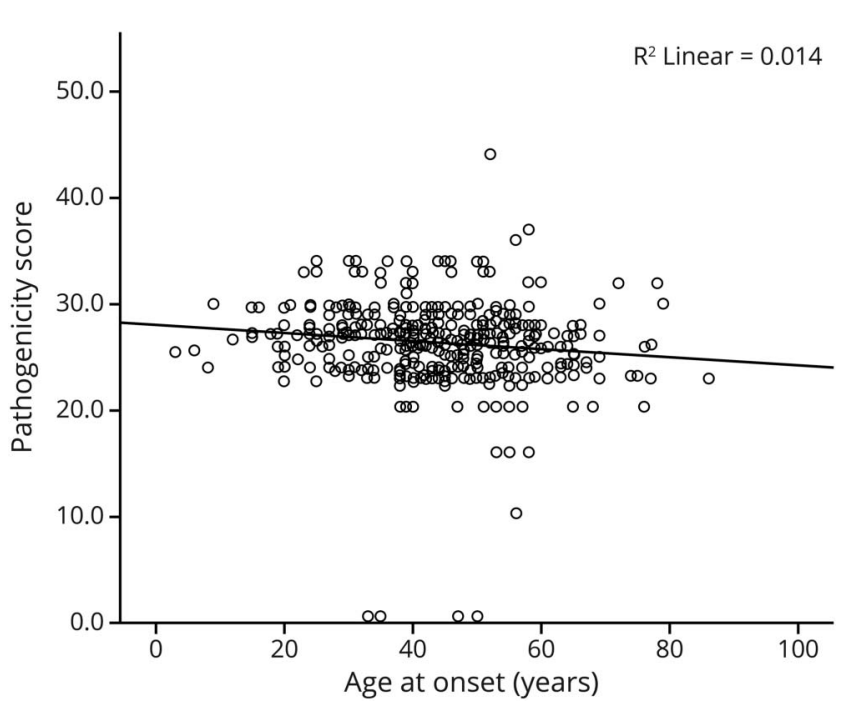

\section{Genotype-phenotype correlation}

Initially, we performed several univariate analyses concerning the associations of all clinical characteristics and phenotypes with genotypic characteristics and pathogenicity scores. We found that the age at onset of CADASIL was significantly associated with the pathogenicity score of the mutation (rho = $-0.165, p<0.001$ ). Highly pathogenic and pathogenic mutations appear to induce an earlier age at onset compared with likely pathogenic, benign, and likely benign variants. The higher the pathogenicity score, the earlier the onset of the disease (figure 5).

Multivariable analyses, taking into account several clinical and genetic factors, further indicate that the age of disease onset was independently $(\mathrm{B}=-0.4,95 \%$ confidence interval $[\mathrm{CI}]=$ -0.7 to $0.1 ; p<0.004)$ associated with pathogenicity score (table e-1, links.lww.com/NXG/A263).

Regarding phenotype severity, women appear to have a different phenotype compared with men $(p=0.003)$, as presented in figure 6. Migraine is more common by $44 \%$ in women than men, while women usually present a less severe phenotype.

Phenotype severity is also highly correlated with age $(p<$ 0.001) (table e-2, links.lww.com/NXG/A264). Migraine is prevalent at the age of 40 years, whereas a more severe phenotype that contains stroke or stroke and migraines is more prevalent in older patients (50-60 years). Cognitive decline or other psychiatric disorders manifest at the same age range (50-60 years) as stroke (figure 7). This indicates a cumulative effect of neurologic deficits with the progression of the disorder. More specifically, the mean age at onset in patients presenting with migraine, stroke and cognitive decline, or other psychiatric disorders is 40,52 and 55 years, respectively.
Pathogenicity score appears to be solely affected by the location of the mutation $(p<0.001)$ and is not associated with phenotype severity (figure 8). All 3 phenotypes described harbor the same pathogenic mutations in qualitative and quantitative analysis.

The clinical manifestations and phenotype severity did not vary significantly between patients harboring cysteine and cysteine-sparing mutations. However, the age at onset was significantly earlier (mean difference $=7.8$ years $95 \% \mathrm{CI}=2.2$, 13.5) in patients with cysteine-sparing mutations $(p=0.009)$. The mean age at onset in patients with cysteine and cysteinesparing mutations was 51 and 43 years old, respectively.

Regarding the clinical profile and the phenotypic characteristics among Asian and Caucasian patients, there are certain signifcant differences. In particular, phenotypes 1 (patients with migraine) and 2 (patients with migraine and stroke or stroke only) of CADASIL were more prevalent in Caucasians than in Asians (figure 3). Regarding distribution of mutations, there are several differences between Asians and Caucasians because cysteine mutations are more prevalent in Asian populations (figure 4).

\section{Discussion}

The present review summarizes the clinical and neuroimaging findings of a novel mutation in exon 19 of the $\mathrm{NOTCH} 3$ gene, the c.3084 G > C, corresponding to the aminoacidic substitution p.Trp1028Cys. We have also documented that type

Figure 6 Bar chart showing the differences between men and women regarding phenotype severity

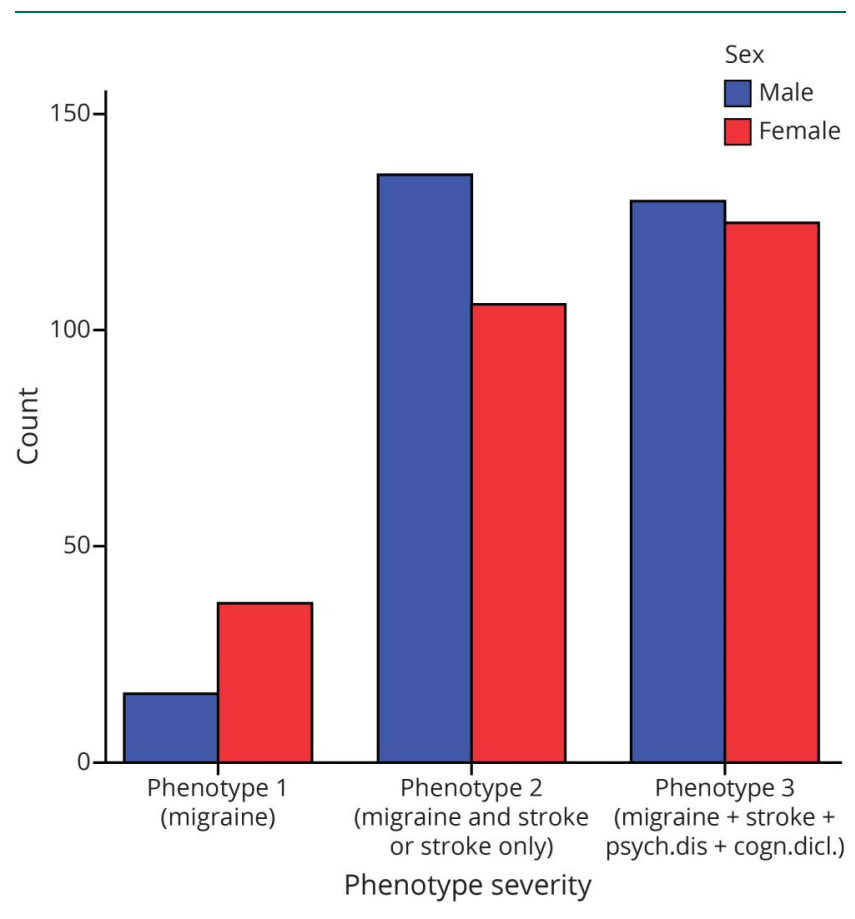

Phenotype severity-sex, $p$ value $=0.003$. 
and pathogenicity of the mutation are independently associated with the age of disease onset. Finally, phenotypic and genotypic characteristics differ significantly between Asians and Caucasians.

Most mutations in the NOTCH3 gene are located within the large extracellular domain (ECD) of the transmembrane receptor. This domain consists of 34 epidermal growth factor (EGF)-like repeats that contain cysteines. The pathogenic mutations are associated with changes in the number of cysteines, leading to a misfolding of the receptor. This misfolding contributes significantly to the formation of oligomers and ECD aggregation, which is considered to be the pathogenic mechanism of the disease. ${ }^{20,21}$

A few mutations have been found that do not affect the number of cysteines. The interesting fact is that these mutations result in an uneven number of cysteine residues. The pathogenic role of these mutations is controversial. ${ }^{22}$ Several of these atypical mutations appear to be associated with conformational changes in the protein similar to the changes observed for typical cysteine involving mutations. However, these mutations seem to cause a similar phenotype without any significant differences regarding the age at onset or phenotype severity. ${ }^{21}$ Our findings clearly demonstrate this concentration of mutations in the ECD domain, especially in exon 4 and $3 .^{23}$ Furthermore, they highlight the significant association of the location of the mutations with pathogenicity score and phenotype severity. We have not found any differences in the age at onset and the clinical phenotype overall regarding the cysteine and cysteine-sparing mutations. These results are consistent with most previous studies in Caucasian or Asian populations. However, there are small regional studies in Taiwan and Korea that presented different results, indicating that the most common mutations were in exon 11 and 18. These differences may simply reflect a founder effect. ${ }^{24,25}$

Our study investigated several possible associations between the genetic profile and clinical manifestations in all previously published cases within the parameters stated earlier. Several studies have thoroughly described the phenotypic manifestations and the natural history of the disorder, evaluating the frequency and age distribution of several characteristics. ${ }^{26}$ There are also other studies, with a limited number of patients, investigating possible phenotypic-genotypic correlation by comparing patients carrying mutations involving cysteine residues with patients with cysteine-sparing mutations without showing any significant differences. ${ }^{27}$

It has also been found that genetic variants located in the EGFr domain 7-34 are identified in the general population, whereas in patients with CADASIL the variants are predominately located in the EGFR 1 . This must be further investigated with wider population studies to elucidate the role of many variants in small vessel disease phenotype.

Skin biopsy is considered an important diagnostic tool for CADASIL diagnosis, highly specific but with variable sensitivity.
Figure 7 Box plot depicting the distribution of phenotypes of CADASIL across age

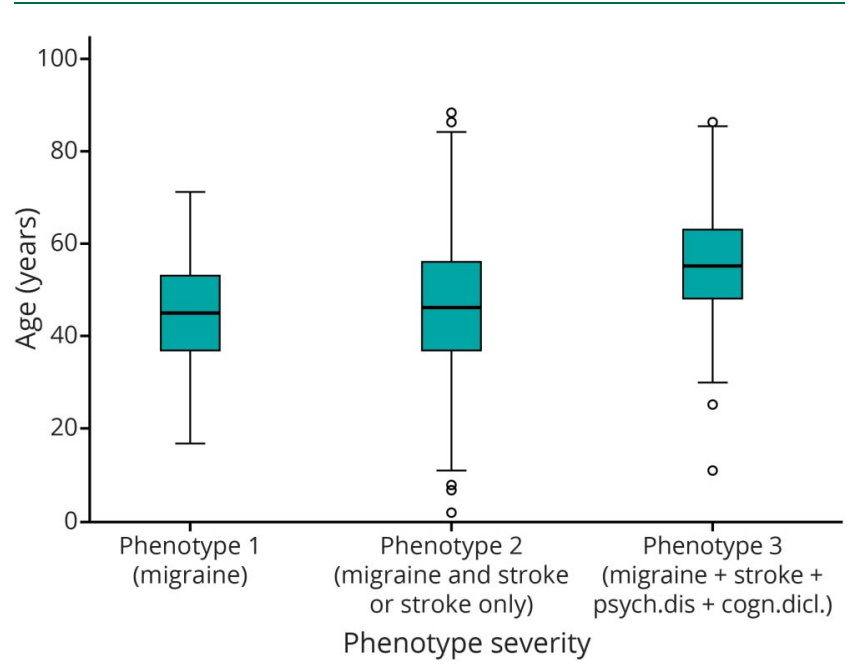

Phenotype severity-age, $p<0.001$.

Many technical factors, related to the actual biopsy or the severity of the disorder, may be the main reasons for the discrepancy across studies regarding the sensitivity of the method. According to our study, it seems that the implementation of this tool is not widely recognized. A small percentage of studies reported electron microscopy studies on skin biopsies or immunohistochemistry analysis using a NOTCH3 monoclonal antibody. ${ }^{28}$ The studies that did not show the typical depositions presented similar phenotype with the most of all the other described cases and involved patients with typical and cysteine sparing mutations as well. In most centers investigating and examining patients with CADASIL phenotype, it seems that skin biopsy is reserved for patients with unclassified variants. Genetic testing is the core diagnostic tool for the disorder. Our described case failed to manifest these characteristic findings with immunochemistry. Electron microscopy studies are more sensitive than immunochemistry. ${ }^{29}$ Technical reasons, the location of the biopsy, and the severity of the disorder could be possible explanations for the lack of typical findings. ${ }^{30}$

Furthermore, we noticed in our study that leukoencephalopathy in MRI scans is reported in most patients with genetically confirmed CADASIL and CMBs in a minority of them. However, a detailed description of MRI findings is not universally followed and so certain clinicoradiological associations cannot be drawn. There are several other radiologic focused studies showing that the MRI lesion load and pattern can vary quite significantly across patients. A consistent finding is the presence of symmetrical white matter hyperintensities on T2-weighted and fuid-attenuated inversion recovery images. ${ }^{31}$ Anterior temporal pole changes have been associated with high sensitivity and specificity for the disorder. External capsule changes also have a high sensitivity but low specificity. The occurrence of CMBs is disproportionate across published cases. ${ }^{32}$ Dilated perivascular spaces and subcortical and cortical atrophy have also been detected. ${ }^{33}$ The only significant finding that was 
Figure 8 Bar chart showing the distribution of mutations across the exons of the gene according to their pathogenicity score

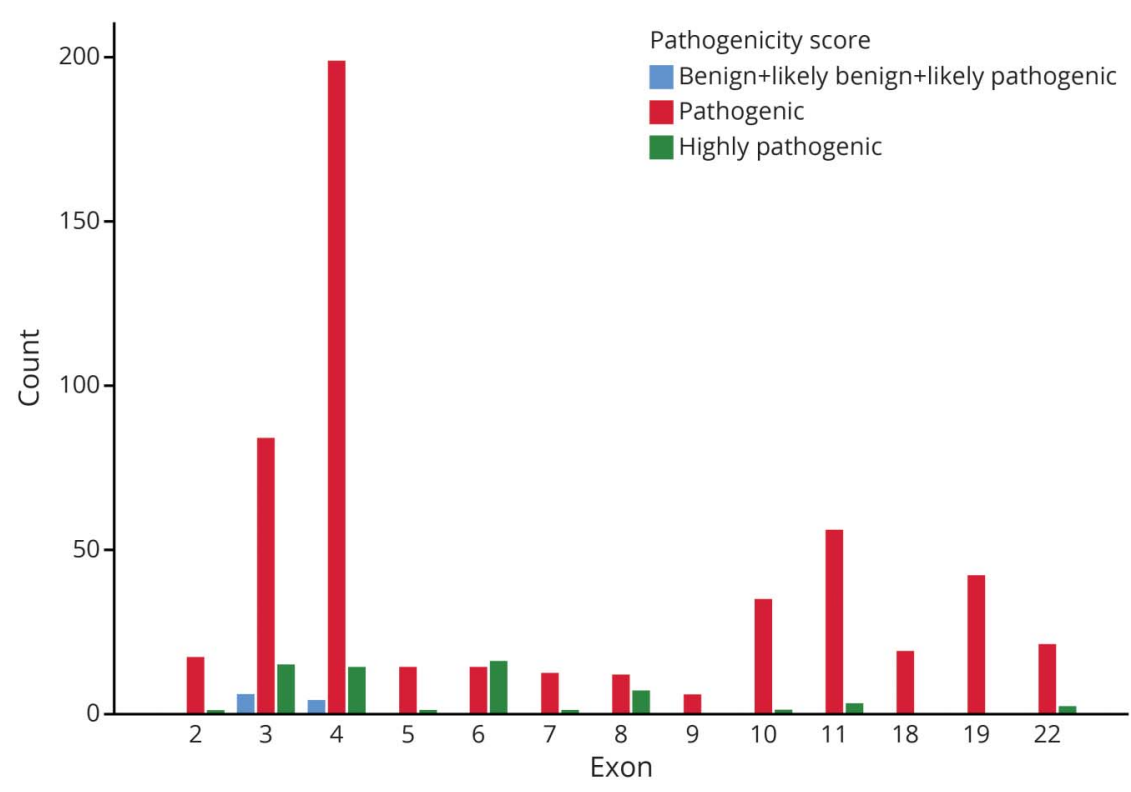

Exon-pathogenicity score, $p$ value $<0.001$

highlighted during our study, with the limited data available, was the fact that MRI CMBs seem to be an age-related phenomenon associated with the progression of the disorder.

Regarding clinical presentation, migraine is often the earliest feature of the disease. According to the previous studies, it seems that migraine is the first clinical symptom in $41 \%$ of symptomatic patients and an isolated symptom in $12 \% .{ }^{34,35}$ Migraine is also reported in approximately 55-75\% of Caucasian cases, although it is less frequent in Asian populations. TIAs and stroke are reported in approximately $85 \%$ of symptomatic individuals. ${ }^{35}$ Several studies have shown that the total lacunar lesion load is strongly associated with the development of disability. ${ }^{4}$ Cognitive impairment in CADASIL involves information processing speed and executive functions mostly. It is also often associated with apathy and depression. Our study presents findings consistent with previous research. However, we managed to investigate the effect of several factors on phenotype severity according to the presence of several clinical symptoms. At some point, the results clearly indicated that phenotype severity is an age-related phenomenon so the disorder seems progressive with the accumulation of new lacunar infarcts that affect cognition. Pathogenicity score does not significantly affect the combination of symptoms that a patient presents, but it appears to be related to the age at onset. We cannot make assumptions based on the pathogenicity of the mutation for the severity of the disorder, so genetic advice should be limited to the presence of the disorder and not to the appearance of specific phenotypic characteristics. Another important clinical conclusion that we drew was the fact that phenotype severity is also affected by sex, with men manifesting more severe symptoms. ${ }^{36}$
Regarding cognitive decline, we should also mention that cognitive performance was either not measured with the same assessments across all studies or it was not performed at all. ${ }^{37}$ Therefore, the presence of impairment is possibly underestimated. Longitudinal studies are also needed to investigate changes related to disease progression and possible association with MRI changes. This will shed light to the pathogenic processes underlying these symptoms. ${ }^{38}$

Other atypical clinical characteristics have also been reported in patients with CADASIL. ${ }^{39}$ A very important manifestation seems to be acute encephalopathy or coma. ${ }^{40}$ This is a rather misleading manifestation that has been reproduced several times in the literature but is extremely rare. Acute encephalopathy has been reported in 2 cases as the initial manifestation of the disorder in our reviewed cases. However, an acute encephalopathic presentation of the disease was previously described in $10 \%$ of patients who were part of a the British CADASIL prevalence study. ${ }^{41}$ All these patients had a history of migraine. The severe symptoms that they presented were episodes of migraine or epileptic seizures that lasted longer than usual, resulting in confusion and disorientation and were self-limited.

Several small cohort studies have previously described specific phenotypic and genotypic characteristics of patients with CADASIL in detail (Supplementary data, links.lww.com/ NXG/A262). They have also focused on specific findings, such as ophthalmologic manifestations, cognitive profile, and MRI features or the effect of other factors such as cardiovascular risk factors on phenotype. ${ }^{42,43}$ Some of these studies include a large number of patients $>200$. However, the clinical and genetic information for every patient separately is not 
publicly available. This fact prevented us from including these patients in our analysis and posed a bias concerning the frequency of mutations across several countries and more detailed genotypic phenotypic correlations.

However, we strongly believe that the collection and analysis of all these scarce data published since the identification of $\mathrm{NOTCH} 3$ qualitatively by means of a systematic review and quantitatively in terms of genetic profile and pathogenicity scores, highlight the significance of the ongoing trend of investigating phenotypic genotypic correlations.

\section{Study funding}

No targeted funding.

\section{Disclosure}

All authors declare that they have no conflicted interests. Go to Neurology.org/NG for full disclosures.

\section{Publication history}

Received by Neurology: Genetics January 7, 2020. Accepted in final form April 2, 2020.

\section{Appendix Authors}

\begin{tabular}{|c|c|c|}
\hline Name & Location & Contribution \\
\hline $\begin{array}{l}\text { Georgia } \\
\text { Xiromerisiou MD, } \\
\text { PhD }\end{array}$ & $\begin{array}{l}\text { University of } \\
\text { Thessaly, Larissa, } \\
\text { Greece }\end{array}$ & $\begin{array}{l}\text { Design and } \\
\text { conceptualized the study; } \\
\text { analyzed the data; drafted } \\
\text { the manuscript for } \\
\text { intellectual content }\end{array}$ \\
\hline $\begin{array}{l}\text { Chrysoula } \\
\text { Marogianni, MD, } \\
\text { MSc }\end{array}$ & $\begin{array}{l}\text { University Hospital } \\
\text { of Larissa, Greece }\end{array}$ & literature search \\
\hline $\begin{array}{l}\text { Katerina Dadouli, } \\
\text { MSc }\end{array}$ & $\begin{array}{l}\text { University of } \\
\text { Thessaly, Larissa, } \\
\text { Greece }\end{array}$ & Statistical analysis \\
\hline $\begin{array}{l}\text { Christina Zompola, } \\
\text { MD }\end{array}$ & $\begin{array}{l}\text { "Attikon" University } \\
\text { Hospital, Athens, } \\
\text { Greece }\end{array}$ & Case description \\
\hline $\begin{array}{l}\text { Georgouli Despoina, } \\
\text { MD, MSc }\end{array}$ & $\begin{array}{l}\text { University Hospital } \\
\text { of Larissa, Greece }\end{array}$ & literature search \\
\hline $\begin{array}{l}\text { Antonios Provatas, } \\
\text { MD, PhD }\end{array}$ & $\begin{array}{l}\text { University Hospital } \\
\text { of Larissa, Greece }\end{array}$ & Data extraction \\
\hline $\begin{array}{l}\text { Aikaterini } \\
\text { Theodorou, MD }\end{array}$ & $\begin{array}{l}\text { "Attikon" University } \\
\text { Hospital, Athens, } \\
\text { Greece }\end{array}$ & Case description \\
\hline $\begin{array}{l}\text { Paschalis Zervas, } \\
\text { MD }\end{array}$ & $\begin{array}{l}\text { "Attikon" University } \\
\text { Hospital, Athens, } \\
\text { Greece }\end{array}$ & Case description \\
\hline $\begin{array}{l}\text { Christina } \\
\text { Nikolaidou, MD }\end{array}$ & $\begin{array}{l}\text { Hippokration } \\
\text { General Hospital } \\
\text { Thessaloniki, } \\
\text { Greece }\end{array}$ & $\begin{array}{l}\text { Histopathologic } \\
\text { examination }\end{array}$ \\
\hline $\begin{array}{l}\text { Stergios Stergiou, } \\
\text { MD }\end{array}$ & $\begin{array}{l}\text { Hippokration } \\
\text { General Hospital } \\
\text { Thessaloniki, } \\
\text { Greece }\end{array}$ & $\begin{array}{l}\text { Histopathologic } \\
\text { examination }\end{array}$ \\
\hline
\end{tabular}

Appendix (continued)

\begin{tabular}{|c|c|c|}
\hline Name & Location & Contribution \\
\hline $\begin{array}{l}\text { Panagiotis Ntellas, } \\
\text { MD }\end{array}$ & $\begin{array}{l}\text { University Hospital } \\
\text { of Ioannina, } \\
\text { Ioannina, Greece. }\end{array}$ & Statistical analysis \\
\hline $\begin{array}{l}\text { Maria Sokratous } \\
\text { MD, MSc }\end{array}$ & $\begin{array}{l}\text { University of } \\
\text { Thessaly, Larissa, } \\
\text { Greece }\end{array}$ & Data extraction \\
\hline $\begin{array}{l}\text { Pantelis Stathis, MD, } \\
\text { PhD }\end{array}$ & $\begin{array}{l}\text { Mediterraneo } \\
\text { Hospital, Athens, } \\
\text { Greece }\end{array}$ & $\begin{array}{l}\text { Revised the manuscript } \\
\text { for intellectual content }\end{array}$ \\
\hline $\begin{array}{l}\text { Georgios P. } \\
\text { Paraskevas, MD, } \\
\text { PhD }\end{array}$ & $\begin{array}{l}\text { National and } \\
\text { Kapodistrian } \\
\text { University of } \\
\text { Athens, Greece }\end{array}$ & $\begin{array}{l}\text { Revised the manuscript } \\
\text { for intellectual content }\end{array}$ \\
\hline $\begin{array}{l}\text { Anastasios Bonakis, } \\
\text { MD,PhD }\end{array}$ & $\begin{array}{l}\text { National and } \\
\text { Kapodistrian } \\
\text { University of } \\
\text { Athens, Greece }\end{array}$ & $\begin{array}{l}\text { Revised the manuscript } \\
\text { for intellectual content }\end{array}$ \\
\hline $\begin{array}{l}\text { Konstantinos } \\
\text { Voumvourakis, MD, } \\
\text { PhD }\end{array}$ & $\begin{array}{l}\text { National and } \\
\text { Kapodistrian } \\
\text { University of } \\
\text { Athens, Greece }\end{array}$ & $\begin{array}{l}\text { Revised the manuscript } \\
\text { for intellectual content }\end{array}$ \\
\hline $\begin{array}{l}\text { Christos } \\
\text { Hadjichristodoulou, } \\
\text { MD, PhD }\end{array}$ & $\begin{array}{l}\text { University of } \\
\text { Thessaly, Larissa, } \\
\text { Greece }\end{array}$ & Statistical analysis \\
\hline $\begin{array}{l}\text { Georgios M. } \\
\text { Hadjigeorgiou, MD, } \\
\text { PhD, }\end{array}$ & $\begin{array}{l}\text { University of } \\
\text { Cyprus, Nicosia, } \\
\text { Cyprus }\end{array}$ & $\begin{array}{l}\text { Interpreted the data; } \\
\text { revised the manuscript } \\
\text { for intellectual content }\end{array}$ \\
\hline $\begin{array}{l}\text { Georgios Tsivgoulis, } \\
\text { MD, PhD }\end{array}$ & $\begin{array}{l}\text { National and } \\
\text { Kapodistrian } \\
\text { University of } \\
\text { Athens, Greece }\end{array}$ & $\begin{array}{l}\text { Interpreted the data; } \\
\text { revised the manuscript } \\
\text { for intellectual content; } \\
\text { case description }\end{array}$ \\
\hline
\end{tabular}

\section{References}

1. Tournier-Lasserve E, Joutel A, Melki J, et al. Cerebral autosomal dominant arteriopathy with subcortical infarcts and leukoencephalopathy maps to chromosome 19q12. Nat Genet 1993;3:256-259.

2. Van Bogaert L. Encéphalopathie sous corticale progressive (Binswanger) à évolutionrapide chez des soeurs. Méd Hellen 1955;24:961-972.

3. Federico A, Bianchi S, Dotti MT. The spectrum of mutations for CADASIL diagnosis. Neurol Sci 2005;26:117-124.

4. Tan RYY, Markus HS. CADASIL: migraine, encephalopathy, stroke and their inter relationships. PLoS One 2016;11:e0157613.

5. O'Sullivan M, Jarosz JM, Martin RJ, et al. MRI hyperintensities of the temporal lobe and external capsule in patients with CADASIL. Neurology 2001;56:628-634.

6. Craggs L, Yamamoto $\mathrm{Y}$, Ihara $\mathrm{M}$, et al. White matter pathology and disconnection in the frontal lobe in cerebral autosomal dominant arteriopathy with subcortical infarcts and leukoencephalopathy (CADASIL). Neuropathol Appl Neurobiol 2014;40:591-602.

7. Goebel HH, Meyermann R, Rosin R, Schlote W. Characteristic morphologic manifestation of CADASIL, cerebral autosomal-dominant arteriopathy with subcortical infarcts and leukoencephalopathy, in skeletal muscle and skin. Muscle Nerve 1997;20: 625-627.

8. Markus HS, Martin RJ, Simpson MA, et al. Diagnostic strategies in CADASIL. Neurology 2002;59:1134-1138.

9. Tikka S, Mykkänen K, Ruchoux M-M, et al. Congruence between NOTCH3 mutations and GOM in 131 CADASIL patients. Brain 2009;132:933-939.

10. Joutel A, Corpechot C, Ducros A, et al. Notch3 mutations in CADASIL, a hereditary adult-onset condition causing stroke and dementia. Nature 1996;383:707-710.

11. Monet-Leprêtre M, Bardot B, Lemaire B, et al. Distinct phenotypic and functional features of CADASIL mutations in the Notch3 ligand binding domain. Brain A J Neurol 2009;132(pt 6):1601-1612.

12. Muiño E, Gallego-Fabrega C, Cullell N, et al. Systematic review of cysteine-sparing NOTCH3 missense mutations in patients with clinical suspicion of CADASIL. Int J Mol Sci 2017; 18:1964.

13. Hack R, Rutten J, Lesnik Oberstein SA (1993). CADASIL. 2000 Mar 15 [Updated 2019 Mar 14]. In: Adam MP, Ardinger HH, Pagon RA, et al. (editors), GeneReviews [Internet]. Seattle (WA): University of Washington, Seattle; 1993-2020. Available from: https://www.ncbi.nlm.nih.gov/books/NBK1500/ 
14. Rentzsch P, Witten D, Cooper GM, Shendure J, Kircher M. CADD: Predicting the deleteriousness of variants throughout the human genome. Nucleic Acids Research 2019;47:D886-D894.

15. Human Splicing Finder-Version 3.1. (n.d.). Available at: umd.be/HSF/. Accessed October 13, 2019.

16. Berkeley's stats website, Statistics for Bioinformatics, Available at: stat.berkeley.edu/ users/mgoldman. Accessed September 2019.

17. Benjamini $Y$, Hochberg Y. Controlling the false discovery rate: a practical and powerful approach to multiple testing. J R Stat Soc Ser B (Methodological) 1995;57: 289-300.

18. Eswaradass VP, Ramasamy B, Kalidoss R, Gnanagurusamy G. Cadasil coma: unusual cause for acute encephalopathy. Ann Indian Acad Neurol 2015;18:483-484.

19. Ragno M, Pianese L, Morroni M, et al. "CADASIL coma” in an Italian homozygous CADASIL patient: comparison with clinical and MRI findings in age-matched het erozygous patients with the same G528C NOTCH3 mutation. Neurol Sci 2013;34: 1947-1953.

20. Lackovic V, Bajcetic M, Lackovic M, et al. Skin and sural nerve biopsies: ultrastructural findings in the first genetically confirmed cases of CADASIL in Serbia. Ultrastructural Pathol 2012;36:325-335.

21. Santa Y, Uyama E, Chui DH, et al. Genetic, clinical and pathological studies of CADASIL in Japan: a partial contribution of Notch3 mutations and implications of smooth muscle cell degeneration for the pathogenesis. J Neurol Sci 2003;212:79-84.

22. Wollenweber FA, Hanecker P, Bayer-Karpinska A, et al. Cysteine-sparing CADASIL mutations in NOTCH3 show proaggregatory properties in vitro. Stroke 2015;46: 786-792.

23. Matsushima T, Conedera S, Tanaka R, et al. Genotype-phenotype correlations of cysteine replacement in CADASIL. Neurobiol Aging 2017;50:169.e7-169.e14.

24. Ueda A, Ueda M, Nagatoshi A, et al. Genotypic and phenotypic spectrum of CADASIL in Japan: the experience at a referral center in Kumamoto University from 1997 to 2014. J Neurol 2015;262:1828-1836.

25. Lee YC, Liu CS, Chang MH, et al. Population-specific spectrum of NOTCH3 mutations, MRI features and founder effect of CADASIL in Chinese. J Neurol 2009; 256:249-255.

26. Rutten JW, Dauwerse HG, Gravesteijn G, et al. Archetypal NOTCH3 mutations frequent in public exome: implications for CADASIL. Ann Clin Translational Neurol 2016;3:844-853,

27. Liu X, Zuo Y, Sun W, et al. The genetic spectrum and the evaluation of CADASIL screening scale in Chinese patients with NOTCH3 mutations. J Neurol Sci 2015;354: 63-69.

28. Dichgans M, Mayer M, Uttner I, et al. The phenotypic spectrum of CADASIL: clinical findings in 102 cases. Ann Neurol 1998;44:731-739.
29. Gustavsen WR, Reinholt FP, Schlosser A. Skin biopsy findings and results of neuropsychological testing in the first confirmed cases of CADASIL in Norway. Eur J Neurol 2006;13:359-362.

30. Morroni M, Marzioni D, Ragno M, et al. Role of electron microscopy in the diagnosis of cadasil syndrome: a study of 32 patients. PLoS One 2013;8:e65482.

31. Dziewulska D, Sulejczak D, Wẹżyk M. What factors determine phenotype of cerebral autosomal dominant arteriopathy with subcortical infarcts and leukoencephalopathy (CADASIL)? Considerations in the context of a novel pathogenic R110C mutation in the NOTCH3 gene. Folia Neuropathologica 2017;55:295-300.

32. Shi Y, Li S, Li W, et al. MRI lesion load of cerebral small vessel disease and cognitive impairment in patients with CADASIL. Front Neurol 2018;9:862.

33. Puy L, De Guio F, Godin O, et al. Cerebral microbleeds and the risk of incident ischemic stroke in CADASIL (cerebral autosomal dominant arteriopathy with subcortical infarcts and leukoencephalopathy). Stroke 2017;48:2699-2703.

34. Wang Z, Yuan Y, Zhang W, et al. NOTCH3 mutations and clinical features in 33 mainland Chinese families with CADASIL. J Neurol Neurosurg Psychiatry 2011;82: 534-539.

35. Guey S, Mawet J, Hervé D, et al. Prevalence and characteristics of migraine in CADASIL. Cephalalgia 2016;36:1038-1047.

36. Burkett JG, Dougherty C. Recognizing CADASIL: a secondary cause of migraine with aura. Curr Pain Headache Rep 2017;21:21.

37. Gunda B, Hervé D, Godin O, et al. Effects of gender on the phenotype of CADASIL. Stroke 2012;43:137-141.

38. Yoon CW, Kim YE, Seo SW, et al. NOTCH3 variants in patients with subcortical vascular cognitive impairment: a comparison with typical CADASIL patients. Neurobiol Aging 2015;36:2443-2447.

39. Brookes RL, Hollocks MJ, Tan RY, Morris RG, Markus HS. Brief screening of vascular cognitive impairment in patients with cerebral autosomal-dominant arteriopathy with subcortical infarcts and leukoencephalopathy without dementia. Stroke 2016;47: 2482-2487.

40. Spinicci G, Conti M, Cherchi MV, Mancosu C, Murru R, Carboni N Unusual clinical presentations in subjects carrying novel NOTCH3 gene mutations. J Stroke Cerebrovasc Dis 2013;22:539-544.

41. Feuerhake F, Volk B, Ostertag C, et al. Reversible coma with raised intracranial pressure: an unusual clinical manifestation of CADASIL. Acta Neuropathologica 2002;103:188-192.

42. Schon F, Martin RJ, Prevett M, Clough C, Enevoldson TP, Markus HS. "CADASIL coma": an underdiagnosed acute encephalopathy. J Neurol Neurosurg Psychiatry $2003 ; 74: 249-252$.

43. Cumurciuc R, Massin P, Pâques M, et al. Retinal abnormalities in CADASIL: a retrospective study of 18 patients. J Neurol Neurosurg Psychiatry 2004;75:1058-1060. 


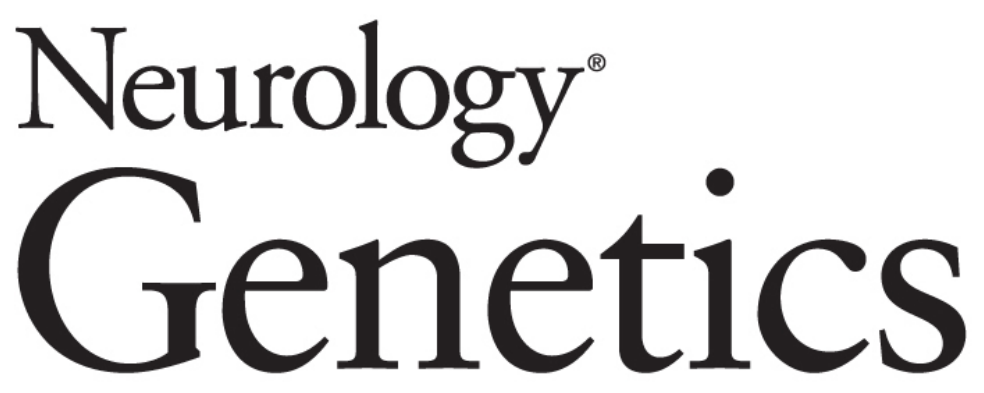

Cerebral autosomal dominant arteriopathy with subcortical infarcts and leukoencephalopathy revisited: Genotype-phenotype correlations of all published cases Georgia Xiromerisiou, Chrysoula Marogianni, Katerina Dadouli, et al. Neurol Genet 2020;6;

DOI 10.1212/NXG.0000000000000434

This information is current as of May 11, 2020

Neurol Genet is an official journal of the American Academy of Neurology. Published since April 2015, it is an open-access, online-only, continuous publication journal. Copyright Copyright ( 2020 The Author(s). Published by Wolters Kluwer Health, Inc. on behalf of the American Academy of Neurology.. All rights reserved. Online ISSN: 2376-7839.

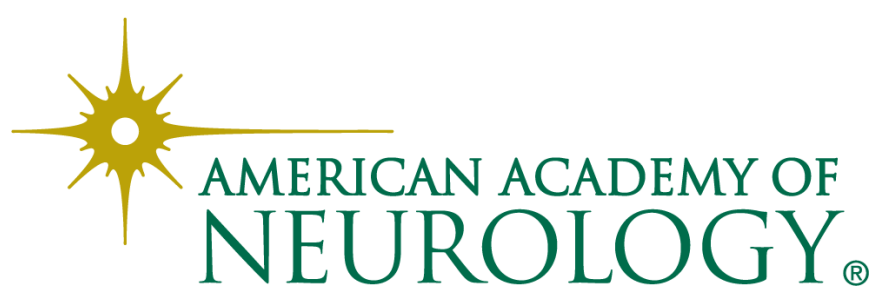




\section{Updated Information \& Services}

References

Citations

Subspecialty Collections

Permissions \& Licensing

Reprints including high resolution figures, can be found at: http://ng.neurology.org/content/6/3/e434.full.html

This article cites 40 articles, 7 of which you can access for free at: http://ng.neurology.org/content/6/3/e434.full.html\#\#ref-list-1

This article has been cited by 1 HighWire-hosted articles: http://ng.neurology.org/content/6/3/e434.full.html\#\#otherarticles

This article, along with others on similar topics, appears in the following collection(s):

\section{All Cerebrovascular disease/Stroke}

http://ng.neurology.org//cgi/collection/all_cerebrovascular_disease_str oke

\section{All Genetics}

http://ng.neurology.org//cgi/collection/all_genetics

Migraine

http://ng.neurology.org//cgi/collection/migraine

MRI

http://ng.neurology.org//cgi/collection/mri

Information about reproducing this article in parts (figures,tables) or in its entirety can be found online at:

http://ng.neurology.org/misc/about.xhtml\#permissions

Information about ordering reprints can be found online:

http://ng.neurology.org/misc/addir.xhtml\#reprintsus

Neurol Genet is an official journal of the American Academy of Neurology. Published since April 2015, it is an open-access, online-only, continuous publication journal. Copyright Copyright $\odot 2020$ The Author(s). Published by Wolters Kluwer Health, Inc. on behalf of the American Academy of Neurology.. All rights reserved. Online ISSN: 2376-7839.

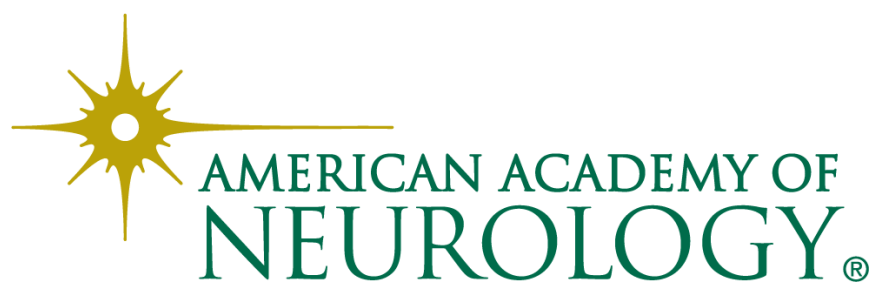

